\title{
ATIVIDADES RÍTMICAS E EXPRESSIVAS NO RITMO DO COTIDIANO ESCOLAR
}

\section{RHYTHMIC AND EXPRESSIVE ACTIVITIES IN EVERYDAY SCHOOL}

\section{ACTIVIDADES RÍTMICAS Y EXPRESIVAS EN EL RITMO DIARIO DE LA ESCUELA}

\author{
Thaís Araújo de Lima ${ }^{1}$ \\ https://orcid.org/0000-0002-5079-0309 \\ Leopoldo Ortega da Silva ${ }^{2}$ \\ http://orcid.org/0000-0003-0001-101X
}

\footnotetext{
${ }^{1}$ Faculdade de Mauá, Mauá, São Paulo - Brasil. E-mail: thais.alima@ hotmail.com.

${ }^{2}$ Faculdade de Mauá, Mauá, São Paulo - Brasil. E-mail: leopoldo.ortega@yahoo.com.br.
}

O trato docente na Educação Física escolar ainda é um desafio na contemporaneidade, sendo agravado pelas conjunturas políticas e sociais em que vivemos. A Base Nacional Comum Curricular (BNCC, 2018) evidencia a necessidade dos professores de ressignificar os saberes sobre a área, tendo em vista atender às demandas da educação básica. O livro que resenhamos neste texto trata-se de uma obra que viabiliza tais demandas, considerando autonomia e didática docente e, ainda, a diversidade de práticas corporais possíveis para as aulas de Educação Física.

Nosso contato com a obra organizada coletivamente por Priscila Raquel Tedesco da Costa Trevisan, Norma Ornelas Montebugnoli Catib, Daniel Amato e Gisele Maria Schwartz se deu, para nós, em contextos muito distintos. A primeira autora desta resenha, na figura de estudante de graduação, e, o segundo, na figura de professor universitário mediador das propostas apresentadas no livro Atividades rítmicas e expressivas no ritmo do cotidiano escolar em um curso de formação de professores de Educação Física (licenciatura). Desse modo, podemos afirmar que a obra se faz relevante para profissionais em diferentes graus de formação e com intencionalidades pedagógicas distintas (formação inicial e/ou mediação do saber na educação básica em todos os níveis). 
O livro publicado em 2016, faz parte de uma coleção com mais de 30 títulos voltados à docência e ao cotidiano escolar. Satisfatoriamente, esta resenha exterioriza o privilégio de termos à disposição um livro com ênfase nas manifestações rítmicas e expressivas e sua inserção no currículo escolar. Trata-se de uma obra inspiradora que contribui para a prática docente alicerçada pela democracia e diversidade cultural, bem como temas para as aulas de Educação Física escolar que contemplem unidades temáticas da Base Nacional Comum Curricular (BNCC, 2018).

Os conceitos do livro são expressos de maneira simples, com proposições viáveis para a Educação Física escolar na contemporaneidade. Os autores apresentam, no decorrer do texto, propostas de atividades que ilustram a prática docente com alternativas didáticas diversificadas em prol da autonomia, do pensamento crítico, da democracia, da promoção de práticas para a saúde e do lazer.

O prefácio, escrito pela Professora Dra. Silvia Deutch, apresenta a obra partindo da reflexão sobre a figura humana e sua constituição pelo movimento composto por ritmo e a expressão. Do grego, ritmo significa fluir, e, nesse contexto, tudo o que se move ou está em movimento revela um ritmo e está presente em diversas facetas e contextos, nas manifestações da natureza, no metabolismo humano, nas produções artísticas da dança, nos jogos, no esporte, na luta e na literatura. Sendo assim, o ritmo nos permite estar em conexão com o nosso interior e em nossas relações com o meio e com o outro, proporcionando abertura e ampliação pedagógica de novos horizontes sobre as manifestações rítmicas e expressivas no contexto escolar. Parafraseando Silvia Deutch, o livro procura preencher uma lacuna na literatura atual acerca do desenvolvimento das atividades rítmicas e expressivas no âmbito escolar.

A organização do texto se estabelece em discussões pautadas em três eixos temáticos:

1) relações entre o ritmo e a arte no contexto escolar;

2) atividades rítmicas;

3) atividades expressivas.

Na introdução, os autores destacam que a formação do professor de Educação Física, na maioria das instituições de ensino superior, é voltada para o aprimoramento da aptidão física, dos esportes coletivos e das ginásticas, ficando para trás ou se esquecendo das experiências que envolvem ludicidade, criatividade, expressividade e a educação rítmica (TREVISAN et al, 2016). 
O livro evidencia a necessidade de atualização dos professores para que aprimorem sua atuação, em especial no ambiente escolar. As proposições da obra aproximam o professor dos temas relacionados à unidade temática dança pautada em abordagens teóricas e práticas, que viabilizam o preenchimento de lacunas inerentes à práxis pedagógica.

No ritmo, mergulhamos no som e na música, correlacionando o corpo e o movimento com a expressividade que se mobiliza pela curiosidade de fazer, potencializando o desenvolvimento humano. Dessa forma, surgem possibilidades de alternativas pedagógicas para o contexto escolar, tendo em vista as manifestações rítmicas e expressivas.

$\mathrm{Na}$ primeira parte do livro ("Relações entre ritmo e arte no contexto da Educação Física"), os autores apresentam e aproximam o leitor, de forma meticulosa e lúcida, de como o ritmo se faz presente no desenvolvimento dos estudantes, considerando a diversidade cultural expressa na individualidade de cada um.

\footnotetext{
A importância do ritmo associado ao movimento vem sendo destacada em diferentes segmentos da sociedade, como fonte de domínio corporal, visando à coordenação motora associada ao uso e deslocamento no espaço, bem como, no fazer artístico e como coadjuvante no processo de educação pelo movimento, no âmbito da Educação Física. (TREVISAN, et al., 2016, p. 19)
}

No desenrolar do texto, os componentes curriculares Arte e a Educação Física ganham destaque nas relações com as manifestações rítmicas e expressivas. Esses componentes propõem a abordagem de atividades rítmicas, da cultura e da expressão como instrumento afetivo e que favoreça a aprendizagem, ampliando estratégias educativas, bem como de conteúdo das aulas.

A segunda parte ("Atividades rítmicas: diferentes formas de expressar o ritmo") discorre sobre as diversas facetas do ritmo e evidencia sua presença em quase tudo e em toda atividade corporal, em especial, as práticas corporais.

O ritmo está em todas as atividades corporais (involuntárias e voluntárias), como: cardíaco, peristáltico, respiratório e digestivo e, ainda, no cotidiano, como, por exemplo, escrever, falar e escovar os dentes. O ritmo pode ser visto em ciclos, como no caso das estações do ano, nos meses, semanas e no tempo marcado pelo relógio. Desse modo, a existência, inclusive a humana, constitui-se das diferentes formas de expressão rítmica.

A terceira parte do livro ("Ritmo, som e música") está organizada em três seções: 

a) Propriedades do som;
b) Figuras rítmicas;
c) Compasso musical.

Apresenta os conceitos musicais para a constituição musical, como, por exemplo, o tempo, as figuras rítmicas, os compassos musicais e o andamento que se fazem igualmente importantes para o desenvolvimento musical e do ritmo em si. Os autores entendem que todos esses conhecimentos são possibilidades de inserção nas aulas, não só na formação da música, mas, também, em inúmeras outras práticas e atividades humanas em que esses aspectos estão presentes.

A quarta parte do livro ("O uso da música como estímulo para o movimento") apresenta uma seção denominada "A música". Nela, os autores discorrem sobre princípios, aspectos e conceitos históricos da música, provocando reflexões sobre as transformações dos conceitos de música ao longo do tempo, assim como o lugar do silêncio na constituição da música. É possível que o leitor faça uma ressignificação de valores e crenças pessoais sobre a música, reconhecendo o papel cultural de sua expressão e, consequentemente, da valorização de saberes multifacetados da música e sua inserção no currículo escolar.

A quinta parte do livro (“Sugestões de atividades com música”) é organizada em seis seções:

a) Atividades para fazer música;

b) Usando o corpo;

c) Usando a voz;

d) Usando objetos;

e) Usando instrumentos musicais artesanais;

f) Usando instrumentos musicais industrializados.

Para muitos que desejam abordar a música como tema ou conteúdo das aulas, o grande desafio está em propor práticas pedagógicas. Nesse sentido, os autores apresentam sugestões de atividades com a música, mostrando objetivos e possibilidades de criação com e pelo corpo, voz, objetos em geral, instrumentos artesanais e industrializados. 
O fazer musical deve ser entendido como a possibilidade de participação da execução de uma ou mais músicas, emitindo sons e/ou silêncio, com intenção de participar da composição musical, ou seja, mediante a participação ativa do músico e/ou compositor. (TREVISAN, et al., 2016, p. 39)

A sexta parte ("Educação rítmica e movimentos") é estruturada em quatro seções:

a) Educação para o movimento rítmico;

b) Sugestões para o desenvolvimento rítmico;

c) Princípios pedagógicos;

d) Propostas de atividades práticas.

Os autores iniciam o capítulo afirmando que o corpo, por meio dos movimentos, traduz subjetividades e tem o ritmo como intermediador direto mediante movimentos como andar, saltar, correr, pular, estender, rolar, subir, descer, girar, entre tantos outros movimentos exercidos pelo corpo e que são utilizados no cotidiano de trabalho, lazer, jogos, brincadeiras, danças e esportes. Vale dizer que as formas que o ser humano tem de gesticular, ir, vir e se comunicar são elementos de linguagem corporal.

Assim, confirma-se a importância do trabalho dos movimentos corporais ligados diretamente à educação rítmica. "A educação rítmica, ao promover a coordenação entre diferentes habilidades e capacidades motoras, facilita a consciência para a ação" (TREVISAN et al., 2016, p. 54). Sugestões didáticas são oferecidas, vislumbrando o desenvolvimento do movimento rítmico na escola, com algumas possibilidades de atividades para inspiração e criação pedagógica.

A sétima parte (“Atividades expressivas”) é estruturada em seis seções:

a) A expressão corporal;

b) A expressividade nas fases do desenvolvimento da infância e adolescência;

c) Sugestão de um programa de atividades expressivas;

d) Sugestão de atividades expressivas;

e) Princípios pedagógicos;

f) Propostas de atividades práticas. 
Os autores questionam o indivíduo quando ele coloca todas as suas necessidades acima dos limites corporais individuais, desejos que podem promover estresse diário, inexistência do sentimento de lazer e ludicidade no cotidiano e tantos outros fatores que ultrapassam suas necessidades básicas e expressivas. Como alternativa para tal o texto aponta a valorização da expressividade no contexto escolar, tendo em vista o desenvolvimento da expressão corporal, respeitando a individualidade de cada um dos estudantes.

Por intermédio dos estímulos das atividades de expressão corporal, o indivíduo pode melhorar relação com seu próprio corpo, por ter oportunidade de se reconhecer. Além disso, estas atividades favorecem a percepção claramente de suas potencialidades. (TREVISAN, et al., 2016, p. 75)

Considerando essas premissas, as estratégias também contribuem para a motivação do professor e dos alunos, atribuindo significados para as práticas e potencializando a superação de desafios individuais e coletivos. A partir de proposições, a participação ativa nas construções didático-pedagógicas das aulas valoriza o processo formativo em oposição ao resultado técnico ou performático. Para tal, sugestões de atividades são dadas, viabilizando a prática docente a partir das manifestações rítmicas expressivas.

A oitava parte do livro (“As danças: diferentes estilos”) é estruturada em 10 seções:

a) Sugestões para orientar o trabalho com a dança na escola;

b) Sugestões para se trabalhar a dança na escola;

c) Danças de salão;

d) Danças urbanas;

e) Danças circulares;

f) Propostas educativas e de sensibilização;

g) Florais de Bach;

h) Legendas para a marcação das danças circulares e dos florais de Bach;

i) Princípios pedagógicos;

j) Propostas de atividades práticas. 
Nessa parte do livro, a dança é considerada uma atividade culturalmente criada e uma manifestação presente em todos os campos da sociedade, tendo diversas finalidades, como divertimento, expressão de sentimentos, descanso, promoção da qualidade de vida e saúde e como um instrumento de comunicação, expressão e linguagem corporal desde os primórdios, além de também estar relacionada intrinsecamente com a musicalidade em diferentes culturas.

Nesse capítulo, os autores apresentam as danças e suas incontáveis facetas, possibilitando, para nós, que resenhamos esse livro, a lembrança de experiências vividas e aprendidas na infância e na adolescência dentro e fora da escola. Tais experiências se materializaram pelas danças populares e do folclore brasileiro, como o carimbó e a quadrilha, adentrando nas danças de salão, como o forró e a salsa, chegando ao mundo das danças urbanas, apresentando o hip-hop, e abrindo novas possibilidades com as danças circulares e os florais de Bach.

Com sugestões de atividades e danças caminhos foram apresentados para aumentar as possibilidades didáticas e pedagógicas para as manifestações rítmicas e expressivas, aproximando a unidade temática da dança ao currículo escolar.

A nona e última parte do livro ("Criatividade relacionada ao ritmo e à expressão") defende a ideia de que, na escola (educação básica), quase não existem atividades de criação; a maioria dos conteúdos propostos em aula é restrita de criação, sendo apresentada aos estudantes de maneira definitiva, limitando as possibilidades de novas descobertas e construções.

Considerando que o aluno tem ampla capacidade criativa e imaginativa, os autores ressaltam que a oferta de estímulos nas aulas pode abrir a possibilidade para novas descobertas, trazendo significados e sentidos para os envolvidos, pois a aprendizagem se torna fruto de uma construção de interesse do próprio estudante.

Embora o livro discuta aspectos relacionados com as manifestações rítmicas no ambiente escolar, muitas reflexões e proposições didáticas apresentadas podem ocupar espaço nos cursos de formação e em contextos extraescolares.

Conhecer, aprender e criar por meio do corpo em movimento se tornam ações indissociáveis, sendo que estratégias flexíveis, as quais permitam a expressão da sensibilidade, da imaginação, da inteligência e, portanto, da criatividade, representam uma forma artística de aprender, inovar e evoluir. Contudo, as atividades rítmicas e expressivas na escola devem ser compreendidas como um meio de educar, criativamente, instigando o desenvolvimento nos níveis motor, cognitivo e afetivo (TREVISAN, et al., 2016, p. 123). 
Os autores direcionam seu olhar diretamente aos professores quando abordam as limitações encontradas no desenvolvimento das aulas de Educação Física e afirmam que eles devem encontrar alternativas criativas e também tecnológicas para essa problemática, diversificando estratégias didáticas que permitam aos estudantes criar novas possibilidades dentro do seu cotidiano, como, por exemplo, transformar situações de conflito em criações artísticas. Dessa maneira, afirmam que o professor passa a ser um transformador, pesquisador crítico, reflexivo e parceiro no processo de aprendizagem do conhecimento.

O processo criativo do estudante depende do incentivo do professor para movimentos livres que valorizem a ludicidade, que instiguem o protagonismo e novas maneiras de criar, potencializando competências e habilidades.

\footnotetext{
Com o exercício da criatividade, o foco recai sobre o aprender a aprender e sobre a necessidade de produzir novos saberes. Tomando por base o corpo expressivo que ultrapassa o papel de aluno reprodutor e repetir de conhecimentos e costumes, esse aluno é colocado em um patamar de indivíduo atuante, produtor de uma cultura dinâmica e vida, construída de acordo com a realidade (TREVISAN, et al., 2016, p. 125).
}

A obra colabora para elucidar alguns questionamentos sobre a unidade temática dança, prevista na Base Nacional Comum Curricular (BNCC, 2018), uma vez que, para muitos, as manifestações rítmicas e expressivas ainda não são entendidas como viáveis para as aulas de Educação Física escolar. Recomendamos a leitura do livro para todos aqueles que se propõem a exercer a tarefa docente, em especial na educação escolar e nos cursos de formação de professores.

\section{Referências}

BRASIL. Base nacional comum curricular (BNCC). Brasília: MEC, 2018. Disponível em: http://basenacionalcomum.mec.gov.br/abase/. Acesso em: 10 abr. 2020.

TREVISAN, P. R. T. da C. et al. Atividades rítmicas e expressivas no ritmo do cotidiano escolar, Curitiba: CRV Editora, 2016, v. 8. 
Recebido em: 05/05/2020

Revisado em: 14/10/2020

Aprovado em: 27/10/2020

Publicado em: 15/03/2021 